\title{
Desenvolvimento de uma régua para medidas de área foliar do algodoeiro
}

\author{
José Fideles Filho ${ }^{1}$, N apoleão E. de M. Beltrão ${ }^{2} \&$ Antonildo S. Pereira ${ }^{3}$
}

\begin{abstract}
RESUMO
O bjetivou-se, através deste trabalho, desenvolver e validar uma régua que mede, de maneira rápida e não destrutiva e diretamente no campo, a área foliar do algodoeiro. Aos 90 dias após a emergência da cultura, amostras de folhas de 10 plantas do algodoeiro, cultivar BRS 187 8H, foram coletadas, das quais se retiraram todas as folhas para composição da amostragem e, em seguida, tiradas cópias xerox, e só então feitas medidas de comprimento e, com o auxílio de um planímetro, mediu-se a área foliar para definir a escala da régua. Em uma segunda etapa se utilizaram as cultivares BRS Safira, BRS 201 e BRS Verde, para testar a régua. A análise de regressão entre a área foliar medida na amostra de folhas e a estimada, obteve bom ajuste com coeficiente de determinação igual a 0,95. Comparando-se as médias entre os dois métodos verificou-se que a média da área das folhas das quatro cultivares do algodoeiro medidas com a régua, não diferiu estatisticamente da área média medida com o planímetro. A régua pode ser recomendada para se fazer medida direta no campo em cultivares de algodão de folhas cordiformes e planofilares, com relação à horizontal.
\end{abstract}

Palavraschave: equação de regressão, folha okra, análise de crescimento

\section{Development of a ruler for measurements of leaf area of the cotton plant}

\begin{abstract}
The objective of this research was to develop and validate a ruler that measures the leaf area of the cotton plant, in a quick and non-destructive manner and directly in the field. $\mathrm{N}$ inety days after the emergence of the crop, leaf samples of tencotton plants of cultivar BRS $1878 \mathrm{H}$ were collected, of which all leaves were removed to prepare the samples and, after that, they were photocopied and length measurements were done with the help of a planimeter to define the range of the ruler. In the second stage of the experiment, the cultivars BRS Safira, BRS 201 and BRS Verde were used to test the ruler. The analysis of regression between the leaf area measured in samples of leaves and the estimated areas showed a good adjustment with coefficient of determination equal to 0.95 . Comparing the means of both the methods, it was verified that the mean leaf area of the four cultivars of cotton, measured with the proposed ruler, did not differ statistically from the mean area measured with the planimeter. The ruler can be recommended to determine, directly in the field, the leaf area of cotton cultivars with cordiform and planofile leaf structure, in relation to the horizontal.
\end{abstract}

Key words: regression equation, okra leaf, growth analysis 


\section{INTRODUÇÃO}

A análise de crescimento é definida como um método descritivo das condições morfofisiológicas das plantas e estuda a dinâmica da produção fotossintética (Magalhães, 1979). Ela se baseia, fundamentalmente, no fato de que cerca de $90 \%$ da matéria seca acumulada pelas plantas ao longo do seu crescimento resultam da atividade fotossintética (Benincasa, 1986). De acordo com o autor, do ponto de vista agronômico a análise de crescimento atende àqueles pesquisadores interessados em conhecer diferenças funcionais e estruturais entre cultivares de uma mesma espécie, de forma a poder selecioná-los para melhor atender aos seus objetivos ou mesmo aplicá-los em programas de melhoramento genético.

O conhecimento da relação entre características de crescimento e desenvolvimento da planta com componentes do rendimento dos genótipos, é determinante para a definição de um tipo de planta mais produtiva (Costa \& Navarro Jr., 2002; Silva et al., 2005).

A área foliar de uma cultura é conhecida como sendo uma variável indicativa de produtividade, pois o processo fotossintético depende da interceptação da energia luminosa e da sua conversão em energia química (Favarin et al., 2002). Desta forma, a superfície foliar de uma planta é base do rendimento de uma cultura (Pereira et al., 1997).

O conhecimento desta variável permite a estimativa da perda de água, já que as folhas são os principais órgãos participantes no processo da transpiração sendo, também, responsáveis pelas trocas gasosas com o ambiente.

A área foliar pode ser medida ou estimada por métodos destrutivos e não destrutivos. Os métodos destrutivos pressupõem colheitas destrutivas de amostras de plantas e da medição da sua área foliar real no laboratório em medidores de área foliar. Esses métodos são simples e precisos (Sommer \& Lang, 1994) mas, além de consumirem muito tempo, têm a grande desvantagem de provocar a destruição de superfície fotossintética, não permitindo o acompanhamento da evolução da área foliar, ao longo do ciclo na mesma planta.

Os métodos não destrutivos podem ser divididos em indiretos e diretos (Lopes et al., 2004). A determinação da área foliar de forma indireta não destrutiva pode ser feita de diversas maneias, destacando-se os modelos empíricos que estimam o desenvolvimento da área foliar em função da temperatura (Bindi et al., 1997), os métodos baseados na extinção da luz através da vegetação (Cohen et al., 2000) e a detecção remota (Dobrowski et al., 2002). Esses métodos são rápidos mas a maioria exige equipamentos caros que necessitam de calibração frequentes e protocolos de medição específicos para cada situação (Ollat et al., 1998).

A área foliar pode ser medida por diversos métodos porém a medição de folhas para cálculo de área foliar é um dos mais adequados, pois é rápido, simples, independente de equipamentos complexos e não destrói a planta, o que permite que a medida seja feita diversas vezes na mesma planta. Vários autores propuseram métodos similares para outras culturas (Lopes et al., 2004; Bianco et al., 2005; 2007).

Segundo Monteiro et al. (2005), a avaliação do desenvolvimento da área foliar do algodoeiro, assim como de outras espécies, pode ser usada para investigar sua adaptação ecológica a novos ambientes, sua competição com outras espécies, os efeitos de seu manejo e tratamentos culturais, a identificação da capacidade produtiva de seus diferentes genótipos e o efeito do ataque de doenças. Na atualidade, por ano são lançadas diversas cultivares de algodão no mundo e, assim, é necessário atualizar o conhecimento sobre a estimativa da área foliar que, junto com a fitomassa das plantas, constitui a base, ou seja, os valores primários, na análise do crescimento, para estimativa das características do crescimento.

Desta forma se objetivou, com este trabalho, desenvolver e validar uma régua linear que possibilita, de maneira rápida e não destrutiva e diretamente no campo, a determinação da área foliar de quatro cultivares de algodoeiro, que servirá como ferramenta na análise de crescimento desta malvácea.

\section{MATERIAL E MÉTODOS}

A pesquisa foi desenvolvida em duas etapas, entre os meses de setembro a dezembro de 2006 e 2007, em área pertencente à Embrapa Algodão, localizada no município de Campina Grande, PB, com as seguintes coordenadas geográficas: latitude $07^{\circ} 13^{\circ} \mathrm{S}$, longitude $53^{\circ} 31^{\prime} \mathrm{W}$ Green wich e altitude $531 \mathrm{~m}$.

O material vegetal utilizado na primeira etapa foi algodoeiro, cultivar BRS 187 8H, definida pela Embrapa Algodão, para confecção da régua.

O plantio foi realizado em vaso de plástico com capacidade para $10 \mathrm{~kg}$ de material de solo mais material orgânico (esterco de curral), semeando-se oito sementes em cada vaso, a céu aberto. Depois da germinação das sementes as plantas foram irrigadas diariamente.

Aos 90 dias após a emergência da cultura (DAE) amostras de folhas de 10 plantas do algodoeiro foram coletadas das quais se retiraram todas as folhas para composição da amostragem e, em seguida, tiradas cópias xerox e feitas medidas do comprimento da nervura principal de cada folha.

Definiu-se o comprimento das folhas como a distância entre o ponto de inserção do pecíolo no limbo foliar e a extremidade oposta da folha (Figura 1), com o auxílio de uma régua milimetrada, e suas áreas determinadas com o auxílio de um planímetro, a partir de duas leituras das áreas de cada folha obtendo-se sua área média.

Os dados coletados foram submetidos a análise de regressão, conforme o modelo proposto por Grimes \& Carter (1969), de acordo com a Eq. 1:

$$
\log (\mathrm{Y})=\mathrm{a}+\mathrm{b} \log (\mathrm{X})
$$

em que $\mathrm{Y}$ representa a área foliar, $\mathrm{X}$ o comprimento da folha, e a e b, coeficientes da equação.

Na segunda etapa se utilizaram, para testar a régua, a cultivar BRS 187 8H como testemunha, e as cultivares BRS Safira, BRS 201 e BRS Verde, também definidas pela Embrapa Algodão. 


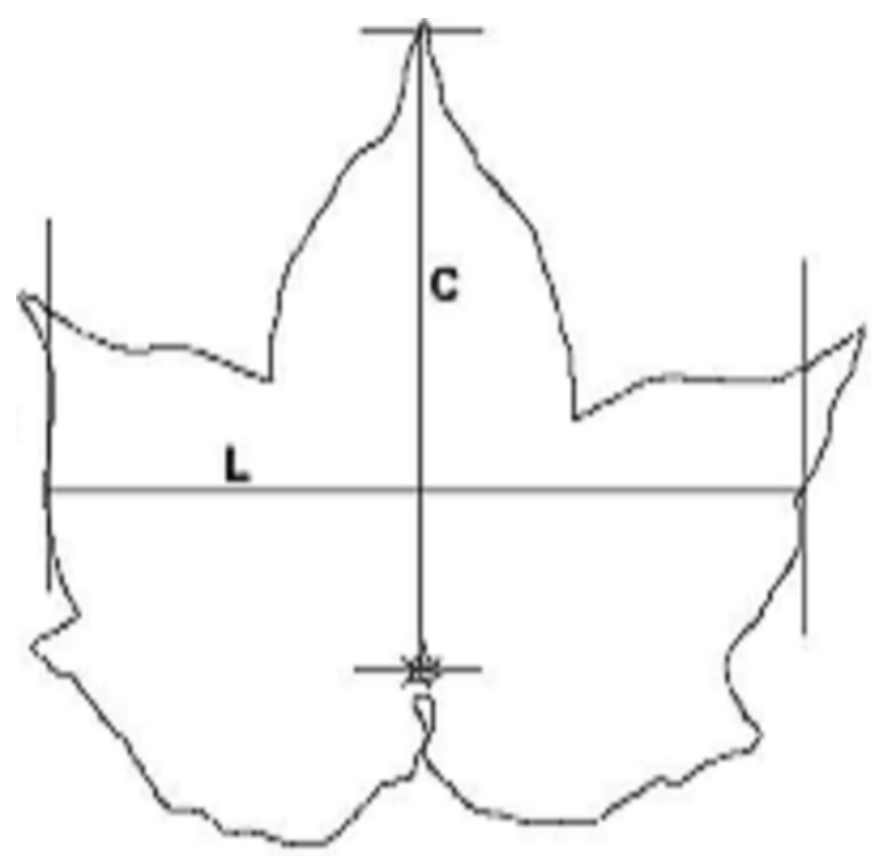

Figura 1. Medidas lineares obtidas nas folhas do algodoeiro: limbo foliar comprimento (C) e largura (L)

O delineamento experimental foi o inteiramente casualizado, com quatro tratamentos que, no caso, foram as variedades do algodoeiro e seis repetições.

Aos 90 DAE as áreas das folhas foram medidas com a régua desenvolvida na etapa anterior; em seguida, foram coletadas folhas, ou seja, as mesmas que foram medidas com régua para se determinar a área através do planímetro. Após as medidas das áreas através dos métodos citados, os mesmos foram comparados para avaliação e validação da régua.

\section{RESULTADOS E DISCUSSÃO}

As medidas do comprimento das folhas coletadas aos 90 DAE e as respectivas áreas reais das folhas obtidas por meio do planímetro, foram submetidas a análise de regressão, onde se observou alto grau de correlação. O coeficiente de determinação para as amostras de folhas pode ser observado na Figura 2. A análise de regressão foi estatisticamente significativa pelo teste F, para p d" 0,01 , com elevado $(0,96)$ coeficiente de determinação (Figura 2).

Estimativas acuradas de área foliar pela equação proposta requerem alta correlação entre a área real medida pelo planímetro e o modelo adotado em que se utiliza apenas o comprimento da folha.

A regressão obtida com a relação entre a área da folha e o comprimento do limbo principal de folhas de algodão, é apresentada na Figura 2. Verifica-se que o modelo apresentou desempenho bastante consistente, visto que evidencia o elevado coeficiente de determinação da regressão $\left(R^{2}=0,96\right)$, em que o mesmo indica o alto grau de associação entre o logaritmo da área foliar e o logaritmo do comprimento da folha para a variedade de algodão.

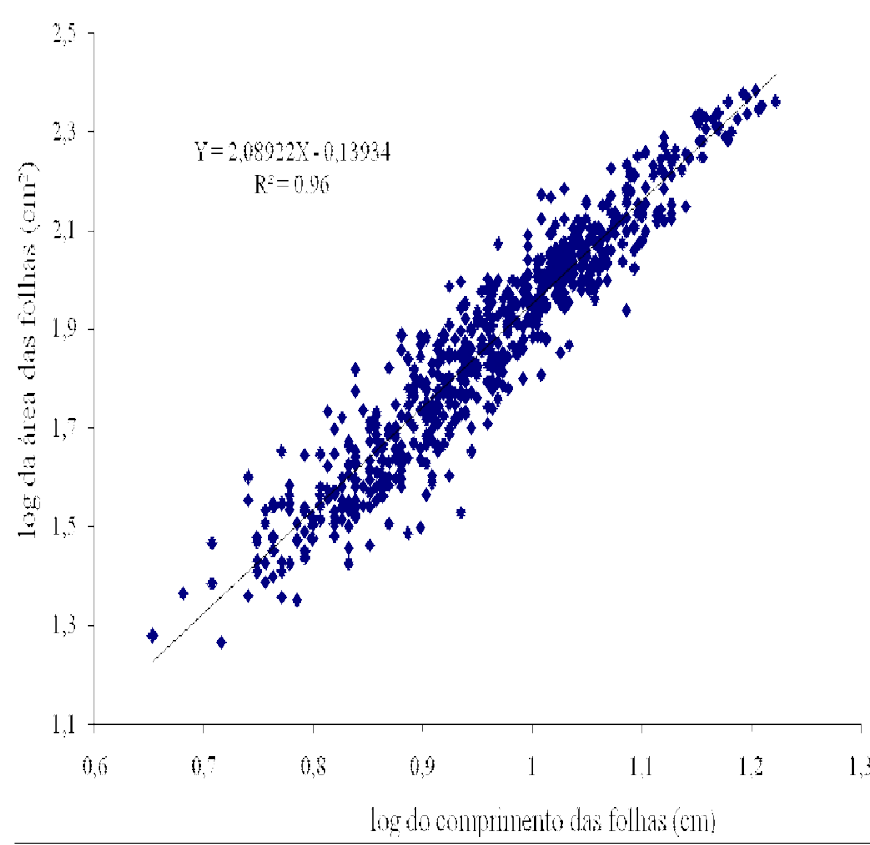

Figura 2. Relação entre área foliar $\left(\mathrm{cm}^{2}\right)$ do algodão cultivar BRS $1878 \mathrm{H} \mathrm{e} 0$ comprimento $(\mathrm{cm})$ do limbo foliar

A equação de regressão da área das folhas em relação ao seu comprimento, na forma de logaritmo, é dada por:

$$
\log (Y)=-0,13954+\log (X)^{2,08922}
$$

em que $\mathrm{Y}$ corresponde à área foliar (AF) e X ao comprimento da nervura principal da folha.

Resolvendo a Eq. 2 para a fórmula potencial:

$$
\begin{gathered}
Y=0,7254(X)^{2,08922} \\
X=1,17(Y)^{0,4786}
\end{gathered}
$$

A Eq. (4) é obtida da (3), pela solução de X por termos de Y. A distância X é agora determinada nos valores selecionados de Y.

Determinaram-se, a partir das Eqs. (3) e (4), as escalas da régua, pelas quais as medidas da área foliar do algodoeiro podem ser realizadas em função do comprimento do limbo principal das folhas diretamente no campo, sem destruir as plantas, utilizando-se a régua apresentada na Figura 3. A escala inferior da régua é dada em centímetros $(\mathrm{cm})$, enquanto a escala superior é dada em centímetros quadrados $\left(\mathrm{cm}^{2}\right)$. Apesar da medição do comprimento da nervura principal ser tarefa fácil e rápida, a estimativa da área foliar total de uma cultura de algodão ainda se torna morosa, caso se queira medir todas as folhas, principalmente quando as plantas estiverem em plena atividade fotossintética e do grau de desenvolvimento da planta.

A régua apresentada na Figura 3 permite a obtenção da leitura direta e não destrutiva da área foliar de cada folha individual de uma planta do algodoeiro no campo sem que seja necessária sua destruição, na qual se tem a relação entre a área foliar e o comprimento das folhas do algodoeiro.

Para aferição e teste da régua desenvolvida, obtiveramse 370 folhas das cultivares do algodoeiro, das quais 87 da 


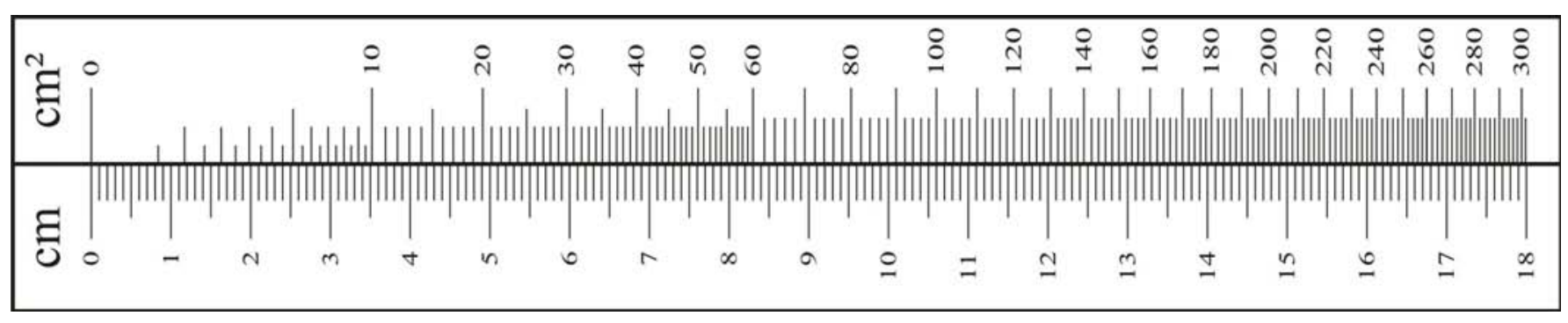

Figura 3. Régua desenvolvida entre a relação do comprimento do limbo foliar do al godoeiro, cultivar BRS $1878 \mathrm{H}$, e sua área (escala em cm e cm²)

BRS Safira, 109 folhas da BRS Verde, 104 folhas da BRS $1878 \mathrm{H}$ e 70 folhas da BRS 201, nas seis repetições de cada variedade, de acordo com o delineamento experimental.

Os resultados da análise de variância dos dados de área foliar estão dispostos na Tabela 1. Observa-se que não houve efeito estatisticamente significativo para média, em nível de $5 \%$ de probabilidade, pelo teste F, nas quatro variedades estudadas. As respostas das variáveis estudadas aos tratamentos, ou seja, as médias das áreas foliar utilizando-se a régua linear nas quatro cultivares do algodoeiro, não foram estatisticamente diferentes.

Tabela 1. Análise da variância obtida a partir das médias das áreas foliares das cultivares de algodoeiro medidas com a régua e com o planímetro

\begin{tabular}{lcccc}
\hline Causas da Variação & G.L & Soma dos Quadrados & Quadrado Médio & Teste F \\
Tratamentos & 3 & 1,7646 & 0,5882 & $0,23 \mathrm{~ns}$ \\
Resíduos & 20 & 51,9917 & 2,5996 & - \\
Total & 23 & 53,7563 & - & - \\
\hline \multicolumn{5}{c}{ Planimétro } \\
Tratamentos & 3 & 32,0683 & 10,6894 & $2,69 \mathrm{~ns}$ \\
Resíduos & 20 & 79,5167 & 3,9758 & - \\
Total & 23 & 111,5850 & - & - \\
\hline
\end{tabular}

"ns" indica que não existem diferenças significativas, pelo teste $\mathrm{F}$ a nível de $5 \%$ de probabilidade

Portanto, a régua linear para realizar medidas da área das folhas do algodoeiro pode ser recomendada para se fazer medida direta no campo em cultivares de algodão de folhas cordiformes e planofilares, com relação à horizontal. O método não se aplica a cultivares de folhas de quiabo (Okra) nem super-okra, que também é denominada quiabo super.

Tabela 2. Análise da variância obtida a partir das médias das áreas foliares das cultivares de algodoeiro medidas entre a régua e com o planímetro

\begin{tabular}{lcccc}
\hline Causas da Variação & G.L & Soma dos Quadrados & Quadrado Médio & Teste F \\
Tratamentos & 1 & 1,5753 & 1,5753 & 1,67 ns \\
Resíduos & 6 & 5,6466 & 0,9411 & - \\
Total & 7 & 7,2219 & - & - \\
\hline
\end{tabular}

"ns" indica que não existem diferenças significativas, pelo teste $\mathrm{F}$ a nível de $5 \%$ de probabilidade
Os resultados da análise de variância dos dados de área foliar obtidos pela régua e pelo planímetro nas cultivares do algodoeiro, estão apresentados na Tabela 2. Comparando-se as médias entre os dois métodos pelo teste de Tukey a 5\% de significância, verificou-se que a média da área das folhas das quatro cultivares do algodoeiro medidas com a régua, não diferiu estatisticamente da área média medida com o planímetro, o que confirma a utilização da régua linear para medida direta e não destrutiva da área das folhas das cultivares do algodoeiro diretamente no campo, com precisão.

Apresentam-se, na Figura 4, as médias das áreas das folhas das quatro cultivares do algodoeiro. Confirmando o resultado da análise da variância, notou-se que o teste de Tukey não detectou diferença significativa entre as médias obtidas pela régua e pelo planímetro. Observa-se ainda, nesta figura que, visualmente, pode-se detectar diferenças entre os dois métodos de medidas nas cultivares BRS 187 8H e BRS Verde, obtendo-se valores médios superiores pelo método do planímetro mas não diferindo estatisticamente. Esta diferença deve ter ocorrido devido a erros de leitura ou até mesmo erro instrumental, enquanto nas cultivares BRS Safira e BRS 201 Marrom as médias obtidas pelos dois métodos não diferem estatística nem visualmente, quando se observa a Figura.

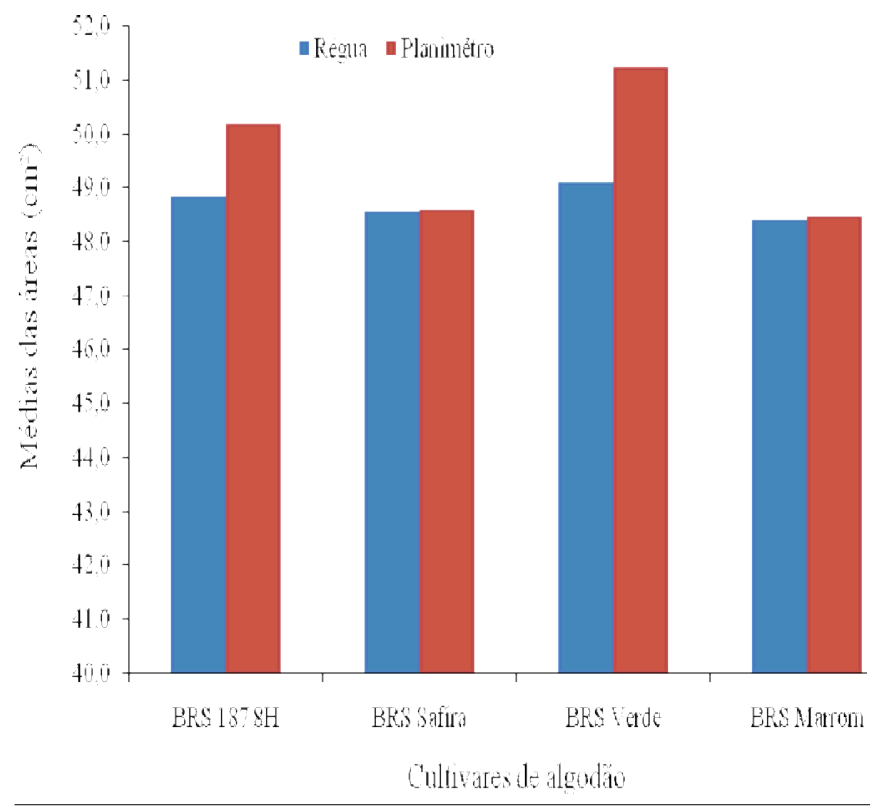

Figura 4. Comparação das médias das áreas foliares das quatro cultivares do al godoeiro utilizando-se os dois métodos 
Vários são os métodos para se determinar a área foliar de uma planta, tais como através de medidas simples de suas dimensões ou de equipamentos sofisticados de alto custo. Alguns autores propuseram diversas formas de se determinar a área foliar de certas cultivares do algodoeiro, através de métodos não-destrutivos, entre eles Grimes \& Carter (1969), que desenvolveram uma régua linear para a estimativa da área foliar do algodoeiro, via uso de uma equação logarítmica, e teve como base uma amostra de 400 folhas, e sem validação para diferentes cultivares desta fibrosa, em especial precoces.

As cultivares utilizadas por Grimes \& Carter (1969) para desenvolver a régua tinham ciclo longo, em torno de 240 dias; ainda hoje a régua é utilizada por vários pesquisadores da área agronômica (Fideles Filho et al., 2005; Cordão Sobrinho et al., 2007) em cultivares de algodão de ciclo médio em torno de 120 dias, e com folhas menores, em pelo menos $30 \%$.

O método do melhoramento genético das plantas de algodoeiro, cujo ciclo das cultivares foi diminuído, maior precocidade, tornou-se necessário uma avaliação na metodologia original, partindo-se da idéia de Grimes \& Carter (1969) e se desenvolveu uma régua utilizando-se medidas lineares de algumas cultivares atuais desta fibrosa.

A maioria dos trabalhos disponíveis na literatura avalia qual dimensão da folha ou do folíolo apresenta melhor correlação com a área da folha e da planta toda, sem dedicar muita atenção às diferenças de forma das folhas; isto reflete a limitação prática inerente ao método que, na verdade, é a maior desvantagem do seu uso, dada à dificuldade de se realizar medidas em um grande número de folhas ou plantas (Monteiro et al., 2005).

A vantagem de se utilizar o método da régua linear é que o mesmo tem a possibilidade de uso com um mínimo de recursos, além de ser utilizado como método não destrutivo. Em trabalhos futuros é possível avaliar alternativas em métodos mais simples que exijam menor número de medidas, levandose em consideração a medida de apenas algumas folhas em posições predeterminadas e o número de folhas por planta, além de tentar correlacionar a área de uma folha do tronco ou vegetativo, e uma reprodutiva ou do fruto, com a área foliar total da planta.

\section{CONCLUSÕES}

1. A área foliar do algodoeiro das cultivares estudadas pode ser medida de forma não destrutiva, com rapidez e precisão, a partir de medidas físicas, fáceis de se obter no campo com a utilização da régua linear.

2. A área foliar do algodoeiro pode ser estimada com boa precisão a partir da medida de comprimento de suas folhas, com régua linear.

3. A régua deve ser recomendada para se realizar medidas de área das folhas em cultivares de algodão de folhas cordiformes e planofilares.

\section{LITERATURA CITADA}

Benincasa, M. M. P. Análise de crescimento de plantas (noções básicas). Jaboticabal: FCAV/UNESP, 1986. 41p.

Bianco, S.; Binco, M. S.; PavniI, M. C. M. D.; Duarte, D. J. Estimativa da área foliar de Ipomoea hederifolia e Ipomoea nil Roth. usando dimensões lineares do limbo foliar. Planta Daninha, v.25, n.2, p.325-329, 2007.

Bianco, S.; Pitele, R.; Bianco, M. S. Estimativa da área foliar de Brachiaria plantaginea usando dimensões lineares de limbo foliar. Planta Daninha, v.23, n.4, p.597-601, 2005.

Bindi M.; Miglietta, F.; Gozinni, B.; Orlandini, S.; Seghi, L. A simples model for simulation of growth and development in grapevine. Model Descrition, v.36, p.67-71, 1997.

Cohen, S.; Striem, M. J.; Bruner, M.; Klein, I. Grapevine leaf área índex evaluation by gap fraction inverson. Acta Horticulturae, v.537, p.87-94, 2000.

Cordão Sobrinho, F. P.; Fernandes, P. D.; Beltrão, N. E. de M.; Soares, F. A. L.; Terceiro Neto, C. P. C. Crescimento e rendimento do algodoeiro BRS-200 com aplicações de cloreto de mepiquat e lâminas de irrigação. Revista Brasileira de Engenharia Agrícola e Ambiental, v.11, n.3, p.284292, 2007.

Costa, J. A.; Navarro Júnior, H. M. Contribuição relativa dos componentes do rendimento para produção em grãos de soja. Pesquisa Agropecuária Brasileira, v.37, n.3, p.269-274, 2002.

Dobrowski, S. Z.; Ustin S. L.; Wolpert, J. A. Remote estimation of vine canopy density in vertically shoot-positioned vineyar$\mathrm{ds}$ : determining optimal vetation inexes. Australian Journal Grape Wine Research, n.8, p.117-125, 2002.

Favarin, J. L.; Dourado Neto, D. ; Garcia, A, G.; Villa Nova, N. A.; Favarin, M. G. G. Equações para a estimativa do índice de área foliar para o cafeeiro. Pesquisa Agropecuária Brasileira, v.27, n.6, p.769-773, 2002.

Fideles Filho, J.; Nóbrega, J. Q.; Sousa, J. T. de; Dantas, J. P. Comparação dos efeitos de água residuária e de poço no crescimento e desenvolvimento do algodoeiro. Revista Brasileira de Engenharia Agrícola e Ambiental, v.9 (suplemento) p.328332,2005 .

Grimes, D. W.; Carter, L. M. A linear rule for direct nondestructive leaf área measurements. Agronomy Journal, v.3, n.61, p.477-479, 1969.

Lopes, C. M.; Andrade, I.; Pedroso, V.; Martins, S. Modelos enpiricos para estimative da area foliar da videira na Casta Jaen. Ciência Técnica Vitivinicultura, v.19, n.2, p.61-75, 2004.

Magalhães, A. C. N. Análise quantitativa de crescimento. In: Ferri, M.G. (coord.). Fisiologia vegetal. São Paulo: Pedagógica Universitária, 1979. p.331-350.

Monteiro, J. E. B. A.; Sentelhas, P. C.; Chiavegato, C. G.; Santiago, C. V.; Prela, A. Estimação da área foliar do algodoeiro por meio das dimensões e massa das folhas. Bragantia, v.64, n.1, p.15-24, 2005.

Ollat, N.; Fernaud, M.; Tandonnet, J. P.; Neveux, M. Evaluation of an indirect method for leaf area index determination in the vineyard: Combined effects of cultivar, year and training system. Vitis, v.37, p.73-78, 1998.

Pereira, A. R.; Villa Nova, N. A.; Sediyama, G. C. Evapotranspiração. Piracicaba: FEALQ, 1997. 183p. 
Silva, A. F.; Silva, F. P.; Pitombeira, J. B.; Barros, L. M.; Bezerra, A. P. L. Interceptação de luz, matéria seca e área foliar de linhagem de algodoeiro herbáceo. Revista Ciência Agronômica, v.36, n.1, p.67-73, 2005 .
Sommer, K. J.; Lang, A. R. G. Comparative analysis of two indirect methods of measuring LAI as applied to minimal and spur pruned grape vines. Australian Journal Plant Physiology, v.21, p.197-206, 1994. 